\title{
Open journey theory: I ntersection of journeying with students and opening up to learning
}

\author{
Pamela Heneise Cone ${ }^{1}$, Tove Giske ${ }^{2}$ \\ 1. Azusa Pacific University, USA. 2. Haraldsplass Deaconess University College, Norway. \\ Correspondence: Pamela Heneise Cone. Address: 718 E. Ada Ave., Glendora, CA 91741 USA. Telephone: \\ 1-626-963-7117. Email: pcone@apu.edu.
}

Received: February 5, 2012

DOI : 10.5430/jnep.v3n11p19

\author{
Accepted: February 25, $2012 \quad$ Online Published: April 15, 2013 \\ URL: http://dx.doi.org/10.5430/jnep.v3n11p19
}

\begin{abstract}
Background: Nursing is concerned with holistic care and spirituality is a recognised domain of nursing, but nurses are ill prepared by their nursing education to provide spiritual care to patients and families. Furthermore, little is known about how students learn about spiritual care through their nursing training and how teachers' can best facilitate this process.

Method: Grounded Theory method was used to collect data from 19 teachers in five focus groups and 42 undergraduate students in eight focus groups in Norway. The semi-structured audio taped interviews were transcribed and analysed through constant comparison until categories became saturated and two substantive grounded theories were developed, a teaching theory and a learning theory.

Results: Further analysis was carried out to merge these two substantive theories to form a teaching-learning theory called Open Journey Theory. Three stages of this journey with openness include: 1) Preparing for spiritual connections with patients, 2) Helping students connect with patients, and 3) Mentoring students through self-reflection. This theory displays a deeper understanding of the mutual process of journeying together toward integration of spirituality in nursing competence.
\end{abstract}

Conclusion: Open Journey Theory addresses spiritual care education in theoretical and practical studies in nursing programs. This theory can guide and assist nursing teachers and nursing students around the world to maximize learning outcomes and thus provide the best possible care for the whole person of the patients under their care.

\section{Key words}

Nursing education, Spiritual care, Qualitative research, Teaching, Learning

\section{I ntroduction}

Spiritual care has a growing focus in health care through research and ongoing debate about its nature, but nurses still report that they are ill prepared for spiritual care in clinical practice ${ }^{[1,2]}$.

The aim of this article is to present Open Journey Theory, a new teaching-learning theory, as a theoretical framework that can facilitate spiritual care. This theory is based on an intersection of a substantive grounded theory for teaching spiritual care and a substantive grounded theory about how undergraduate nursing students learned to care for patients spiritually. 
For nurses, the ICN Code of Ethics ${ }^{[3]}$ clearly states our responsibility to address spirituality as part of care for patients' and their families' faith and value systems. There is not yet a commonly agreed definition of spirituality in nursing; however, spirituality is described in relation to hope, meaning, belonging, and faith ${ }^{[4]}$, as well as connectedness ${ }^{[5,6]}$. Some critique spirituality and argue that it is all about psychosocial needs ${ }^{[7]}$. Studies done by the WHO Quality of Life Spirituality, Religion and Personal Beliefs group have developed eight facets that distinguish spirituality from psychosocial care. They are:

- Connectedness to a spiritual being or force,

- Meaning of life,

- Awe,

- Wholeness and integration,

- Spiritual strength,

- Inner peace/serenity/harmony,

- Hope and optimism, and

- Faith $^{[8]}$.

The literature evidences nurse insecurity and a lack of sufficient training to provide spiritual care ${ }^{[2,4,9-11]}$. However, no clear guidelines for teaching spiritual care exist for curricular design in nursing theory or clinical practice ${ }^{\text {[11-14] }}$. Most studies report on educational courses and curricular changes ${ }^{[14-18]}$, but qualitative research from the perspective of students and teachers is limited. Only a few studies were found that deal with the role of the teacher in working with students to gain competences in spiritual care ${ }^{[9,12,19]}$. Furthermore, little focus is given to how clinical studies impact spiritual care learning ${ }^{[1]}$.

Teaching-Learning Theory is a construct that combines teaching strategies with basic learning principles and is a process

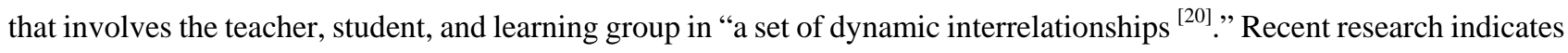
that students' perceptions of their learning experience rate the knowledge of the teacher as the most important element in their learning process in both the clinical and didactic environments. In their recent report on excellence in teaching, Holmes, Baker, and Stowell discuss research-based teaching strategies that facilitate learning, including e-learning ${ }^{[21]}$. Many of these strategies, such as jigsaw, circle of voices, and peer partnerships, revolve around collaborative learning ${ }^{[22,23]}$. Examination of current research reveals many studies in the area of e-learning ${ }^{[21,24,25]}$; technological advances are having a profound impact on education as students turn to online learning experiences in preference over face-to-face opportunities ${ }^{[24,26]}$. Much of the research also focuses on teaching strategies and pedagogy ${ }^{[24]}$. However, clinical education is almost entirely done in face-to-face formats, and exploration of multiple databases and educational association websites revealed no current research comparing the perspectives of nursing teachers and students on face-to-face learning of spiritual care through clinical preparation and experiences.

Spiritual care education is focused on preparing the student to address personal values and to find meaning and hope when working with their patients ${ }^{[18]}$. This focus is closely related to the importance of becoming more self-aware and of clarifying own values, which is widely reported in the literature ${ }^{[19,27-31]}$. It is interesting to note that there is much discussion about how personal characteristics, in both students and teachers, influence spiritual care teaching and learning ${ }^{[4,30,31]}$, which brings both the students' and the teachers' perspective into the discussion.

\section{Method}

\subsection{Research design}

Classical Grounded Theory was chosen as the methodology for the original study. That project had two different foci, students and teachers. In keeping with Glaser's approach, data were gathered concurrently with data analysis and memo writing ${ }^{[32,33]}$. 


\subsection{Participants}

Inclusion criteria were English speaking undergraduate nursing students and teachers at three university colleges in Bergen, Norway. Two were smaller Christian schools and one was a larger secular public school. Participants were recruited after leaders in each school gave permission for the study. For the students, eight focus group interviews were conducted with a total of 42 students ${ }^{[34]}$. Three were with 1st year students, three with 2nd, and two with 3rd year students. With teachers, five focus group interviews were held, three at one site and one each at the two other ${ }^{[27]}$. For details about the participants, see Table 1.

Table 1. Demographics of students and teachers participating in the study

\begin{tabular}{|c|c|c|c|c|c|}
\hline Age & Gender & View of Life & Education Level & Other Education & Level of Teaching \\
\hline \multirow{6}{*}{$\begin{array}{l}\text { Students: } \\
25.6 \text { yrs } \\
(20-45)\end{array}$} & \multirow{6}{*}{$\begin{array}{l}\mathrm{F}: 38 \\
\mathrm{M}: 4\end{array}$} & Christian: 30 & & & \\
\hline & & Religious: 2 & 1st year: 16 & Pedagogics $=1$ & \\
\hline & & Agnostic: 3 & 2nd year: 11 & Psychology $=1$ & \\
\hline & & Atheist/humanist: 2 & 3rd year: 15 & Social Science $=1$ & \\
\hline & & Gnostic: 2 & & Biblical Studies $=1$ & \\
\hline & & Naturalist: 1 & & & \\
\hline \multirow{13}{*}{$\begin{array}{l}\text { Teachers: } \\
49.3 \text { yrs } \\
(36-61)\end{array}$} & \multirow{13}{*}{$\begin{array}{l}\mathrm{F}: 18 \\
\mathrm{M}: 1\end{array}$} & & & Pedagogics $=6$ & \\
\hline & & & & Counseling $=4$ & \\
\hline & & & & Public Health Nursing $=2$ & \\
\hline & & & & Anesthetics $=3$ & 1st year: 5 \\
\hline & & & & Geriatrics $=2$ & 2nd year: 6 \\
\hline & & Christian: 16 & BSN: 3 & Evidence Based Practice $=2$ & 3rd year: 2 \\
\hline & & Humanist: 2 & MS: 15 & Management $=2$ & \\
\hline & & Unknown: 1 & PhD: 1 & Psychology $=1$ & 1st \& 2nd: 1 \\
\hline & & & & Social Science $=1$ & 2nd \& 3rd: 1 \\
\hline & & & & Diaconal Education = 1 & Unknown: 4 \\
\hline & & & & Theology $=1$ & \\
\hline & & & & Methods = 1 & \\
\hline & & & & Neuro-Science $=1$ & \\
\hline
\end{tabular}

\subsection{Data collection}

Data were collected through focus group interviews at each school. The authors were the primary co-investigators and conducted all the interviews. Student interviews took place during their lunch breaks and in breaks between classes. The teacher interviews were scheduled at various times according to availability of the participants. After filling in anonymous demographic sheets, participants were invited to share their thoughts and experiences around questions such as:

- What is spiritual care? How did you learn to give it?

- Tell us about experiences related to spiritual care.

- Teachers also were asked: How do you teach spiritual care?

Interviews were taped and transcribed verbatim ${ }^{[34]}$.

\subsection{Data analysis}

Transcripts were read and manually coded from the first interview. Constant comparison, first with open coding, was used to identify the main concerns of students and teachers and to discover patterns of how they resolved it. When those were understood, the co-investigators moved on to selective and then theoretical coding to relate the concepts into two 
substantive grounded theories. During analysis, it became evident that differences in history, tradition, and culture between Norway and the US challenged the two researchers to understand more deeply and to make more explicit how Norwegian values of individualism, moderation, and privacy relate to how spirituality is understood and expressed.

After the two substantial grounded theories were developed, the authors started to discuss the similarities in the processes

of teaching and learning ${ }^{[27,34]}$. Since the teacher and student data were gathered at the same level of education, there is a natural fit between these emergent theories. Their intersection forms Open Journey Theory.

\subsection{Ethics}

Both studies were accepted by the Norwegian Social Science Data Service (NSD) after assuring anonymity of participant data on the demographic sheets. Permission was obtained from each University College, and full disclosure about the study was provided. Consent was assumed by voluntary attendance at focus groups.

\section{Results}

The two basic social processes that emerged as substantive grounded theories of teaching and of learning are presented briefly before a new teaching-learning theory, developed through continued analysis of these two theories, is introduced. The new theory is Open Journey Theory. Table 2 displays the three stages of the new theory and how the two original theories were merged to form it.

\subsection{Teaching theory}

Journeying with Students through Maturation in Spiritual Care emerged as the basic social process that resolved the main concern ${ }^{[32]}$ of undergraduate nursing educators whose goal was to help students recognize cues and ways of providing spiritual care to their patients. The process has three iterative phases: 1) Raising student awareness of the essence of spirituality, 2) Assisting students to overcome personal barriers to patient care, and 3) Mentoring students' spiritual care competency development ${ }^{[27]}$. Each phase of this substantive grounded theory has several sub-categories, most of which dovetail nicely with the student learning theory.

\subsection{Learning theory}

Opening up to Learning Spiritual Care also emerged as a substantive grounded theory that describes a basic social process. This theory has a focus on the students' main concern of how to create a professional relationship with patients and maintain rapport when spiritual concerns are recognized. The three iterative phases each have two sub-categories that intersect well with the teaching theory. These phases include the following: 1) Preparing for connection at a deep level, 2) Connecting with and supporting patients, and 3) Reflecting on clinical experiences ${ }^{[34]}$.

\subsection{Open journey theory: A teaching-learning theory}

Examination of the two theories revealed clear connections between them, prompting the researchers to consider combining them into a teaching-learning theory. Most of the subthemes between the two theories parallel each other and/or intersect conceptually. On integrating them, the formal teaching-learning theory of Open Journey Theory emerged. This new theory provides a framework that guides and assists nursing teachers and students to maximize student learning outcomes to provide the best possible care for the whole person of the patients under their care. The teaching-learning theory focuses on teachers mentoring student nurses to become more aware of the kinds of issues, concerns, and needs that affect the patient's spirit, to dare to connect deeply with patients, and to reflect on their nurse-patient spiritual care experiences. The new theory describes the journey of teachers and students, both with open attitudes, through student learning and maturation (see Table 2). 
Table 2. Open Journey Theory
TEACHING THEORY
LEARNING THEORY
1. Preparing for spiritual connections with patients
Raising student awareness of the essence of spirituality
a. Promoting self-reflection and group discussion
Preparing for deep connection with patients
b. Assigning readings, requiring journaling, and
a. Knowing oneself more deeply
role modeling spiritual care
b. Preparing in class and on one's own

\section{Helping students to connect with patients}
Assisting students to overcome personal barriers
a. Modeling mutuality and how to balance professional boundaries and personal being
b. Encouraging students to have openness, respect, tolerance and the courage to handle existential pain

\section{Connecting with and supporting patients}
a. Connecting in mutual vulnerability
b. Supporting patients respectfully

\section{Mentoring students through self-reflection}

Mentoring students' spiritual care competency

a. Requiring Spiritual Care on student papers, care plans, and exams throughout the program

b. Promoting group reflection, sharing of spiritual care experiences, and collaboration with others

Note. Teaching theory is in italics - Learning theory is in regular fon

The newly derived phases are iterative, though the process of mentoring carries the connotation of forward movement, much like a helix, where there is a cycle of learning that continues to grow as long as the students and teachers continue to collaborate, thus moving the students toward maturation. The three stages begin with initial preparation, move on to clinical practice followed by self-reflection, and proceed toward competency in spiritual care.

The first stage, Preparing for spiritual connections with patients, requires clear student learning outcomes related to spirituality, communication, and self-awareness as well as good pedagogical preparation by teachers and a readiness on the part of students to become open and willing to get to know oneself more profoundly. By raising student awareness to the spiritual domain, teachers prepare students for deep connections with their patients. Students describe the importance of listening to examples and group discussions where they can talk with each other about topics they had not thought about before, and thus, they learn to know themselves and each other more deeply. Self-reflection is crucial at this point, and having students write in their journals about their journey of self-awareness increases and solidifies their personal insight. In addition, thoughtfully chosen readings and well-done role plays help students, both in class and on their own, to better prepare for their clinical experiences.

Helping students to connect with patients is the second stage; it involves the actual nurse-patient encounters where spiritual concerns and cues are recognized and acted upon by nursing students. Everyone brings personal ways of thinking and feeling to the nursing education experience, and all have personal barriers to overcome when working with patients. Knowing how to balance professional boundaries with the mutual vulnerability that is needed in some patient situations only comes with openness and experience. It is the job of the teacher to model and encourage respect and tolerance when students work with patients, particularly when they have a different belief system or set of values than the student nurse. Furthermore, there are many situations when patients are experiencing deep existential pain where ignoring spiritual angst and cues would be the easy route. It takes a great deal of courage to work at a deep level with patients who are experiencing anxiety and pain, whether physical or emotional. Teachers shared many examples where they demonstrated that they saw this to be part of the teacher's role. 
Mentoring students through self-reflection, the final stage, is a fundamental part of the process that promotes spiritual care learning in clinical studies and on into professional practice. The long-term goal is for the student to become mature enough to be able to form and keep a professional relationship with patients who experience diverse existential pain. It does not necessarily mean that the student is the one to support the patient, since being able to collaborate with other professionals is also an important part of spiritual care competency. This requires careful planning and repeated insertion of appropriate reading materials as well as testing students on these concepts, attitudes, and actions. Care plans and case studies that address the difficult areas of patient experiences are necessary in order to provide students with a framework where they can reflect on their actions in clinical situations in order to identify strengths and challenges in their patient care actions and attitudes. Group reflection, where students can share their experiences with each other, provides opportunities for students to learn from each other, since they are unlikely to all have the breadth of experience needed to grow into maturity in patient care.

\section{Discussion and implications}

Teaching theory, for the nurse educator, is an approach that focuses on teaching pedagogy and utilizing the most effective strategies to stimulate critical thinking and problem-solving among students ${ }^{[35]}$. The teaching theory, Journeying with Students through Maturation in Spiritual Care ${ }^{[27]}$, describes a process that is aimed at integration of learning into practice by use of teaching strategies such as role play, group reflection, and journaling that stimulate critical thinking and promote understanding of difficult concepts. This is a critical part of Open Journey Theory. The focus of learning theory is the other side of the coin, which addresses the unique characteristics of the learner and the setting where learning takes place in order to optimize student learning outcomes ${ }^{[36]}$.

Effective teaching-learning can only occur when students are collaboratively engaged in both the teaching and learning processes. Writing about the teaching-learning process, Bradford states:

Teachers and learners engage together in a complex process of exploration and diagnosis of needs for and resistances to learning and change; of experimentation and fact-finding; of testing and planning for utilization of learning and change in the life of the individual. The relationships among learners and between teacher and learners have a great deal to do with the ultimate learning ${ }^{[20]}$.

Student-centered teaching is aimed at engaging students in a process that is relational and creative in order to develop 'cutting edge' learning experiences for students ${ }^{[37]}$. Collaborative or cooperative learning is a major focus among today's students, both with peers and teachers ${ }^{[22]}$, though there is evidence that it is the collaborative nature of the work, not the assignment itself that is so effective ${ }^{[26]}$. A current meta-analysis of research on student learning supports this focus on group reflection and collaborative learning for optimizing student learning integration into practice ${ }^{[23]}$.

With Open Journey Theory, the learning experience is launched in the first stage with a focus on student engagement and group collaboration, which is an evidence-based educational strategy ${ }^{[23]}$. Selected readings on difficult concepts are introduced early to raise student awareness to the idea of caring for the spirit; research on nursing education in spiritual care has shown this to be very effective ${ }^{[4,38]}$. Teachers provide role plays and group discussions to promote this process. Self-awareness is increased through both personal and group reflection and journaling ${ }^{[35,38]}$; such reflexive critical thinking assists students to identify and overcome personal boundaries. At times, it takes great courage on the part of the student to stay with a patient who is experiencing existential pain and see her or him through a crisis. This "courage to be", as discussed by Paul Tillich ${ }^{[39]}$, enables one to embrace life in spite of challenging situations. This courage is important in order to overcome feelings of inadequacy in clinical settings; it is crucial if there is insufficient training and preparation for spiritual care when students move into clinical practice ${ }^{[2,40]}$. Over the course of the nursing program, new concepts that relate more specifically to the content of specific classes and clinical rotations can be introduced that will help students connect spiritually with their patients in the clinical setting ${ }^{[41,42]}$. Teacher mentoring of students assists student reflection 
on their nurse-patient interactions and enhances learning of spiritual care. In addition, questions included on tests remind the students about the importance of their patients' spiritual domain. Mentoring students through self-reflection helps them to recognize spiritual cues from patients and to develop a repertoire of strategies, such as good listening and communication skills as well as mindful and respectful presence with their patients ${ }^{[38,40]}$.

Spiritual care education has a focus on enlarging the student's world and bringing about a change in attitude and a willingness to try new ways of interacting with patients ${ }^{[1]}$. With patients who have a Christian faith, readings from biblical and theological literature can be introduced to support spiritual care interventions in care plans. For patients of other faith traditions, appropriate sacred works or supportive writings can be used at patient request. Some patients have no particular faith tradition, and they need to be treated respectfully according to what is most important to them rather than the healthcare provider. Case studies that include spiritual issues, whether religious, faith-tradition, or existential in nature provide avenues for students to explore many issues that relate to the spiritual domain ${ }^{[41]}$. As the undergraduates reach their final courses, high level nursing care plans should be expected that incorporate spiritual care into daily patient care. Moreover, the use of papers and exams promotes knowledge retention and learning sensitivity, which are major goals in helping nursing students learn to provide spiritual care ${ }^{[19]}$.

\section{Conclusion}

Nurses are usually not prepared by their nursing education to address the spiritual, religious, and existential needs of patients ${ }^{[12]}$. There has been no apparent effort to include the eight facets of spirituality as described by the WHO research group studying the Quality of Life Spirituality, Religion and Personal Beliefs, into nursing curricula ${ }^{[8]}$. In spite of the ICN and WHO requisite for nurses to provide spiritual care to their patients, nursing education around the world has failed to deliver adequate nurses training in the spiritual domain ${ }^{[1,2,6,9,12]}$. Nursing curricula has yet to develop guidelines for incorporating spiritual care into clinical practice ${ }^{[1,12,13,42]}$, and few role models can be found in clinical settings for students to emulate in learning how to provide spiritual care ${ }^{[27,34]}$.

Journeying with Students through Maturation in Spiritual Care ${ }^{[27]}$, with its focus on the teacher's role in the educational process, and Opening up to Learning Spiritual Care ${ }^{[34]}$, which focuses on the student's perspective on learning, intersect to form Open Journey Theory. This new theory addresses the lack of spiritual care education in nursing programs by threading the content using a mentoring process throughout the nursing program, an effective structure for interactional learning. The process incorporates care at various levels of patient-nurse rapport and intimacy. It includes a vulnerability and mutuality of teacher and student that is eventually reflected in the student nurse-patient interaction that will ultimately influence clinical practice. When the theory is supported with good teaching pedagogy, the student's clinical preparation in spiritual care is enhanced, resulting in improved student learning outcomes.

Open Journey Theory is a teaching-learning theory developed through research on spiritual care education. It is conceptually broad enough, however, to be helpful in planning student learning experiences for many areas with concepts that are difficult to teach and/or understand and integrate into clinical practice. Open Journey Theory provides a structure that can assist nursing teachers and students alike to give the best possible care in all aspects or domains of the patients under their care.

\section{References}

[1] Giske T. How undergraduate nursing students learn to care for patients spiritually in clinical studies: a review of literature. J of Nursing Management. 2012; 20: 1049-1057. PMid:23151107

[2] Cockell N, McSherry M. Spiritual care in nursing: an overview of published international research. Journal of Nursing Management. 2012; 20: 958-969. PMid:23151098 
[3] ICN. Code of Ethics. International Council of Nurses, 2006. Accessed March 6th 2012. Available from: http://www icnch/images/stories/documents/about/icncode_english pdf

[4] Ross L. Teaching spiritual care in nursing: an overview of research to date. J of Clinical Nursing. 2006 ; 15 : 582-562. PMid:16879378 http://dx.doi.org/10.1111/j.1365-2702.2006.01617.x

[5] Cone PH. Connecting: the experience of giving spiritual care. In The Intersystem Model. BM Artinian \& MM Conger. Thousand Oaks, CA: Sage. 1997: 270-288.

[6] Rykkje L, Eriksson K, Råholm MB. A qualitative metasynthesis of spirituality from a caring science perspective. Intl J for Human Caring. 2011; 15(4): 40-53.

[7] Paley J. Spirituality and nursing: a reductionist approach. Nursing Philosophy. 2008; 9: 3-18. PMid:18154633 http://dx.doi.org/10.1111/j.1466-769X.2007.00330.x

[8] WHO Quality of Life Spirituality, Religion and Personal Beliefs [QOL SRPB Group]. A cross-cultural study of spirituality, religion and personal beliefs as components of quality of life. Social science \& Medicine. 2006; 62: 1486-1497. PMid:16168541 http://dx.doi.org/10.1016/j.socscimed.2005.08.001

[9] Lemmer C. Teaching the spiritual dimension of nursing care: A survey of US baccalaureate nursing programs. J of Nursing Education. 2002; 41(11): 482-490. PMid:12437053

[10] Tanyi RA. Towards clarification of the meaning of spirituality. J of Advanced Nursing. 2002; 39(5): 500-509. PMid:12175360 http://dx.doi.org/10.1046/j.1365-2648.2002.02315.x

[11] Carson VB. What is the essence of spiritual care? J of Clinical Nursing. 2011 (July/Sept):173. http://dx.doi.org/10.1097/CNJ.0b013e31821f10a6

[12] Meyer CL. How effectively are nurse educators preparing students to provide spiritual care? Nurse Educator. 2003; 28(1): 185-190. PMid:12878898 http://dx.doi.org/10.1097/00006223-200307000-00010

[13] Stern J, James S. Every person matters: enabling spirituality education for nurses. J of Clinical Nursing. 2006; 15(7): 897-904. PMid:16879382 http://dx.doi.org/10.1111/j.1365-2702.2006.01663.x

[14] McSherry W. The meaning of spirituality and spiritual care within nursing and health care practice. London, England: Quay Books, 2007.

[15] McEwen M. Analysis of spirituality content in nursing textbooks. J of Nursing Education. 2004; 43(1): 20-30. PMid:14748531

[16] Taylor EJ. Spiritual care: nursing theory, research, \& practice (2nd ed.), Upper Saddle River, NJ: Prentice-Hall, 2007.

[17] Van Leeuwen R. Toward nursing competencies in spiritual care. The Netherlands: A University of Groningen Thesis, 2008.

[18] Wallace M, Campbell S, Grossman SC, Shea JM, Lange JW, Quell TT. Integrating spirituality into undergraduate nursing curricula. Intl J of Nursing Education Scholarship. 2008; 5(1): article 10. PMid:18384268 http://dx.doi.org/10.2202/1548-923X.1443

[19] Catanzaro AM, McMullen KA. Increasing nursing students’ spiritual sensitivity. Nurse Educator. 2001; $26(1)$ : $221-226$. PMid:12144340 http://dx.doi.org/10.1097/00006223-200109000-00011

[20] Bradford LP. The teaching-learning transaction (p. 135). Adult Education Quarterly. 1958; 8(3): 135-145. http://dx.doi.org/10.1177/074171365800800303

[21] Holmes J, Baker SC, Stowell JR. Essays from Excellence in Teaching: volume XI. Society for the Teaching of Psychology, 2012. http://teachpsych.org/ebooks/eit2011/index.php

[22] Sahin A. Effects of Jigsaw III technique on achievement in written expression. Asia Pacific Education Review. 2011; 12(3): 427-436. http://dx.doi.org/10.1007/s12564-010-9135-8

[23] Tomacho TJ, Foels R. Meta-analysis of group learning activities: empirically based teaching recommendations. Teaching of Psychology. 2012; 39(3): 159-169. http://dx.doi.org/10.1177/0098628312450414

[24] IJRLHE. International Journal of Teaching and Learning in Higher Education, 2013. Available from: http://www.isetl.org/ijtlhe/

[25] Taylor \& Francis Online. College Teaching: 1985 to current. Available from: http://www.tandfonline.com/toc/vcol20/current

[26] Putnam M, Ford K, Tancock S. Redefining online discussions: using participant stances to promote collaboration and cognitive engagement. Intl J of teaching and Learning in Higher Ed. 2013; 24(2): 151-167.

[27] Cone PH, Giske T. Teaching spiritual care - a grounded theory study among undergraduate nursing educators. J of Clinical Nursing. 2012 (online): 1-9. http://dx.doi.org/10.1111/j.1365-2702.2012.04203.x

[28] Van Leeuwen R, Cusveller B. Nursing competencies for spiritual care. J of Advanced Nursing. 2004; 48(1): 234-246. PMid:15488037 http://dx.doi.org/10.1111/j.1365-2648.2004.03192.x

[29] Mitchell DL, Bennett MJ, Manfrin-Ledet L. Spiritual development of nursing students: developing competence to provide spiritual care to patients at the end of life. J of Nursing Education. 2006; 45(9): 365-370. PMid:17002083

[30] Taylor EJ, Mamier I, Bahjri K, Petersen F. Efficacy of a self-study program to teach spiritual care. J of Clinical Nursing. 2008; 18(8): 1131-1140. PMid:19207790 http://dx.doi.org/10.1111/j.1365-2702.2008.02526.x 
[31] van Leeuwen R. Toward nursing competencies in spiritual care. Thesis, University of Groningen, Netherlands: 2008.

[32] Glaser BG. Theoretical sensitivity: Advances in the methodology of grounded theory. Mill Valley, CA: Sociology Press, 1978.

[33] Artinian BM, Giske T, Cone PH. Glaserian grounded theory in nursing research: Trusting emergence. New York: Springer, 2009.

[34] Giske T, Cone PH. Opening up to learning: a grounded theory study of nursing student education on spiritual care. J of Clinical Nursing. 2012; 21: 2006-2015. PMid:22568656 http://dx.doi.org/10.1111/j.1365-2702.2011.04054.x

[35] Deyoung S. Teaching strategies for nurse educators (2nd ed.). New York: Prentice Hall, 2008.

[36] Young LE, Patterson, BL. Teaching nursing: developing a student-centered learning environment. Philadelphia: Lippincott Williams \& Wilcox, 2007.

[37] Young LE, Maxwell B. Student-centered teaching in nursing: from rote to active learning. In Teaching nursing, by LE Young \& BL Patterson. Philadelphia: Lippincott Williams \& Wilcox, 2007.

[38] Pesut B. Developing spirituality in the curriculum: worldviews on intrapersonal connectedness interpersonal connectedness. Nursing Education Perspectives. 2003; 24: 290-294. PMid:14705397

[39] Tillich P, Gomes, P. The courage to be (2nd ed.). New Haven, CN: Yale University Press, 2000.

[40] Rammal E. Perspectives \& perceptions: spiritual care and organizational climate in Christian schools. J of Christian Nursing. 2010; 27(2): 91-95.

[41] Callister LC, Bond AE, Matsumura G, Mangum S. Threading spirituality throughout nursing education. Holistic Nursing Practice. 2004; 18(3): 160-166. PMid:15222604

[42] Kelly C. Student's perceptions of effective clinical teaching revisited. Nurse Education Today. 2007; $27(8)$ : 885-892. PMid:17321013 http://dx.doi.org/10.1016/j.nedt.2006.12.005 